\title{
Effects and side-effects of partial ileal by-pass surgery for familial hypercholesterolaemia
}

\author{
O FÆRGEMAN*, H MEINERTZ, E HYLANDER, K FISCHERMAN, \\ $S$ JARNUM, and O V NIELSEN
}

From the Department of Medicine B, Department of Medicine P, Division of Gastroenterology, and Department of Surgical Gastroenterology C, Rigshospitalet, Copenhagen, Denmark

SUMmARY Ten patients with familial hypercholesterolaemia were subjected to partial ileal by-pass surgery. Plasma cholesterol fell by 41 and $38 \%$ and low-density lipoprotein cholesterol by 51 and $46 \%$ after six and 18 months respectively. High-density and very low-density lipoprotein cholesterol and plasma triglycerides were unaffected. Alanine aminotransferase increased transiently in half of the patients. Diarrhoea and slight steatorrhoea troubled most of the patients for the duration of the 18 months' period of observation. Other long-term side effects were slight but significant increase in the renal excretion of oxalic acid and reduction in the intestinal absorption of calcium. The study shows that this operation has metabolic side-effects that warrant continued medical care of these patients.

Partial ileal by-pass surgery is in general more effective than drug treatment of familial hypercholesterolaemia. It is also cheaper and poses no problems of patient compliance. Whereas much is known about the side-effects of the jejunoileal by-pass operation for obesity, ${ }^{1}$ little is known about other than the most obvious side-effects of the partial ileal by-pass for hypercholesterolaemia. We have studied effects on plasma lipoproteins as well as several possible side-effects in patients operated on because of familial hypercholesterolaemia in the heterozygous form.

\section{Methods}

\section{PATIENTS}

Criteria for the diagnosis were (1) raised lipoprotein cholesterol concentration, (2) similarly affected first-degree relative, and (3) normotriglyceridaemia. Details of the patients are given in the Table. In all cases, family history indicated a high risk of premature ischaemic heart disease. They had all been instructed to follow a cholesterol-lowering diet, ${ }^{2}$ but adherence was variable. They were asked to continue the diet postoperatively. Previous attempts at

\footnotetext{
- Address for correspondence and reprint requests: Ole Færgeman, Medica Department I, Aarhus Amtssygehus, Tage Hansens Gade 2, 8000 Aarhus C, Denmark.

Received for publication 17 December 1981.
}

pharmacological cholesterol reduction had been unsatisfactory, and, at the time of operation, they were not in treatment with lipid-lowering drugs.

The operation was performed essentially as described by Buchwald et al. ${ }^{3}$ The small intestine was transsected either $200 \mathrm{~cm}$ from the ileocaecal valve or between the proximal two-thirds and distal one-third whichever procedure by-passed the largest segment. The distal ileal segment was closed, duplicated, and fixed to the mesentery to avoid invagination. The proximal segment, the jejunum, was anastomosed end-to-side to the ascending colon 6-8 cm distal to the ileocaecal valve (for details, see reference 3).

The patients were followed closely in the outpatient clinic and studied while they were in hospital before as well as six and 18 months after the operation. Of the 20 patients operated on to date, 10 have been followed for 18 months. The present study deals with these 10 patients, except as otherwise stated.

After an overnight fast, plasma lipoproteins were separated into very low-density lipoprotein, lowdensity lipoprotein, and high-density lipoprotein by ultracentrifugation of plasma at $d 1.006 \mathrm{~g} / \mathrm{ml}$ for 108 $\times 10^{6} \mathrm{~g} \times \mathrm{min}$, removal of very low-density lipoprotein as the supernatant material, and precipitation of low-density lipoprotein from the infranatant material with heparin-manganese. ${ }^{4}$ Cholesterol $^{5}$ and triglycerides ${ }^{6}$ were measured in 
Table Characteristics of patients

\begin{tabular}{|c|c|c|c|c|c|c|c|c|}
\hline \multirow[b]{2}{*}{ Patient } & \multirow[b]{2}{*}{ Sex } & \multirow{2}{*}{$\begin{array}{l}\text { Age (yr) at } \\
\text { operation }\end{array}$} & \multirow{2}{*}{$\begin{array}{l}\text { Ischaemic } \\
\text { heart disease }\end{array}$} & \multirow{2}{*}{$\begin{array}{l}\text { Tendon } \\
\text { xanthomas }\end{array}$} & \multicolumn{3}{|c|}{$\begin{array}{l}\text { Cholesterol } \\
{\text { (mmol/l plasma })^{*}}^{*}\end{array}$} & \multirow{2}{*}{$\begin{array}{l}\text { Triglyceride } \\
\text { (mmol/l plasma) } † \\
\text { Total }\end{array}$} \\
\hline & & & & & total & $L D L$ & $H D L$ & \\
\hline KN & $\mathbf{M}$ & 39 & - & - & $11 \cdot 7$ & $8 \cdot 6$ & $1 \cdot 16$ & $2 \cdot 4$ \\
\hline LT & $\mathbf{M}$ & 29 & - & - & $11 \cdot 1$ & $10 \cdot 1$ & 0.75 & 0.9 \\
\hline PB & $\mathbf{M}$ & 38 & + & - & 9.7 & $8 \cdot 1$ & 0.90 & 1.0 \\
\hline FP & $\mathbf{M}$ & 49 & + & + & $10 \cdot 5$ & $10 \cdot 2$ & $0 \cdot 88$ & $1 \cdot 1$ \\
\hline SS & $\mathbf{M}$ & 32 & - & + & $14 \cdot 3$ & 11.5 & 0.90 & $1 \cdot 3$ \\
\hline CS & $\mathbf{M}$ & 50 & - & + & 11.9 & 9.8 & $1 \cdot 19$ & 0.9 \\
\hline IC & $\mathbf{F}$ & 45 & - & + & 6.8 & $5 \cdot 2$ & 1.06 & $1 \cdot 2$ \\
\hline SN & $\mathbf{F}$ & 41 & - & + & $15 \cdot 9$ & $13 \cdot 4$ & 1.63 & $1 \cdot 3$ \\
\hline SE & $\mathbf{M}$ & 26 & - & - & 8.4 & $6 \cdot 8$ & 1.36 & 0.5 \\
\hline JV & $\mathbf{F}$ & 33 & - & - & 14.9 & $10 \cdot 5$ & 0.83 & $2 \cdot 8$ \\
\hline \multicolumn{5}{|c|}{ Normal range } & $3 \cdot 5-6 \cdot 7$ & $1 \cdot 9-5 \cdot 3$ & $0 \cdot 50-1 \cdot 70$ & $0.5-2.9$ \\
\hline
\end{tabular}

* $1 \mathrm{mmol} / \mathrm{l}=38.7 \mathrm{mg} / 100 \mathrm{ml}$.

$+1 \mathrm{mmol} / \mathrm{l}=88.5 \mathrm{mg} / 100 \mathrm{ml}$.

whole plasma and in the $d>1.006 \mathrm{~g} / \mathrm{ml}$ infranatant before and after heparin-manganese treatment.

During a one-week hospital admission, the patients were studied on a controlled diet providing $70 \mathrm{~g}$ fat, $800 \mathrm{mg}$ calcium, and $200 \mathrm{mg}$ oxalic acid per 24 hours. $^{7}$ After an equilibration period of three days, stools and urine were collected over four 24-hour periods, and the following procedures were performed: (1) stools were weighed, homogenised, and analysed for fat; ${ }^{8}(2)$ oxalic acid in urine was measured as described by Archer et al, ${ }^{9}$ and intestinal absorption of oxalate was estimated by measurement of ${ }^{14} \mathrm{C}$ in urine after oral administration of ${ }^{14} \mathrm{C}$ oxalate, ${ }^{7}(3)$ absorption of calcium from the gut was determined by comparison of radioactivity in the forearm after an intravenous and subsequent 20 times larger peroral dose of ${ }^{47} \mathrm{Ca}$ as described by Curtis et al; $;^{10}$ and (4) bone mineral content was estimated by bone densitometry - that is, measurement of absorption of ${ }^{241} \mathrm{Am}$ emitted gamma rays by a forearm. ${ }^{11}$ Intravenous urography and cholecystography as well as routine blood analyses were performed by standard methods in the Departments of Radiology and Clinical Chemistry.

Statistical analyses were performed with Wilcoxon's rank sum test and Spearmen's rank correlation test.

\section{Results}

Six and 18 months after the operation, the plasma cholesterol concentration had decreased significantly by 41 and $38 \%$ respectively, from a median of 11.9 to 7.1 and $7.4 \mathrm{mmol} / \mathrm{l}$ (Fig. 1). Low-density lipoprotein cholesterol decreased from a median of 10.4 to 4.9 and $5.4 \mathrm{mmol} / \mathrm{l}$ over the same time periods, or by 51 and $46 \%$ respectively. Very low-density lipoprotein and high-density lipoprotein cholesterol were unchanged, as were total very low-density lipoprotein, low-density lipoprotein, and high-density lipoprotein triglycerides (Fig. 2). In two patients, marked but unquantified regression of xanthelasmata and tendon xanthomata occurred.

Moderate diarrhoea and steatorrhoea troubled most patients. This was reflected in significant increases in stool mass $(p<0.01)$ and faecal fat ( $p$ $<0.05$ ) (median $427 \mathrm{~g} / 24$ hours corresponding to $209 \%$ increase in median value and $8 \mathrm{~g} / 24$ hours corresponding to $167 \%$ increase respectively after six months) that persisted after 18 months ( $436 \mathrm{~g} / 24$ hours corresponding to $216 \%$ increase and $9 \mathrm{~g} / 24$

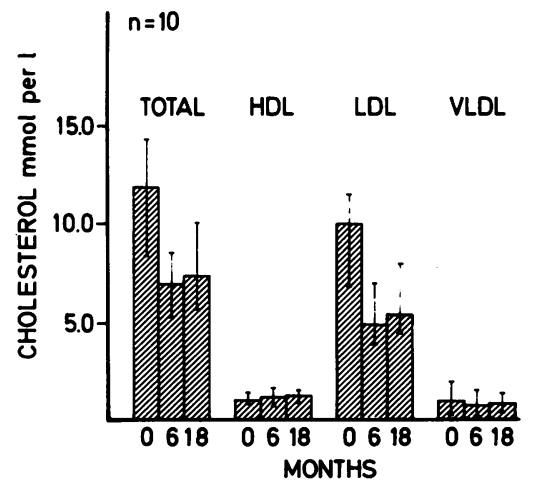

Fig. 1 Cholesterol in plasma and in lipoprotein classes before and six and 18 months after partial ileal by-pass surgery. Medians and 10th and 90th percentiles.

$1 \mathrm{mmol} / \mathrm{l}=38.7 \mathrm{mg} / 100 \mathrm{ml}$. 


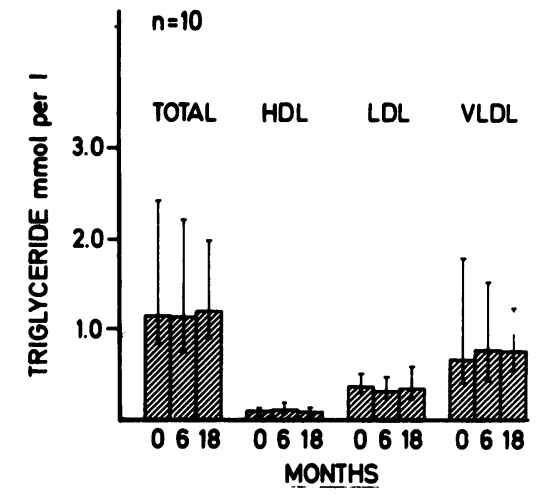

Fig. 2 Triglyceride in plasma and in lipoprotein classes before and six and 18 months after partial ileal by-pass surgery. Medians and 10th and 90 th percentiles.

$1 \mathrm{mmoll}=88.5 \mathrm{mg}$ triolein $100 \mathrm{ml}$.

hours corresponding to $200 \%$ increase) (Figs. 3 and 4). In contrast, a small but significant reduction in body weight ( $p<0.001$ ) was transitory in most patients (Fig. 5). Thus, six and 18 months after the operation the median body weight had decreased by 6 and $1 \%$ respectively. Patients $\mathrm{KN}$ and JV, preoperatively moderately obese, sustained a substantial but desirable 13 and $21 \%$ loss of body weight, respectively.

As shown in Fig. 6, 24 hour renal excretion of

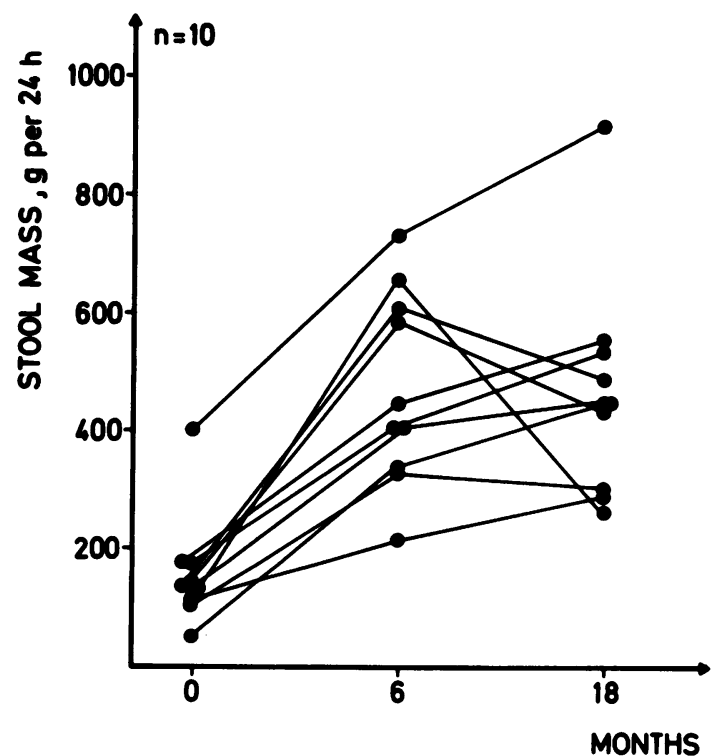

Fig. 3 Stool mass before and six and 18 months after partial ileal by-pass surgery.

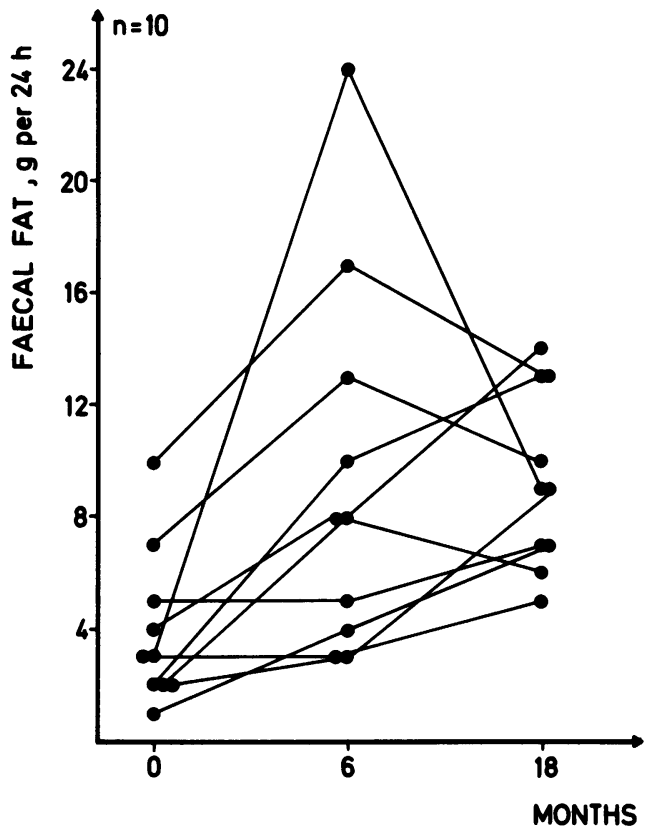

Fig. 4 Faecal fat before and six and 18 months after partial ileal by-pass.

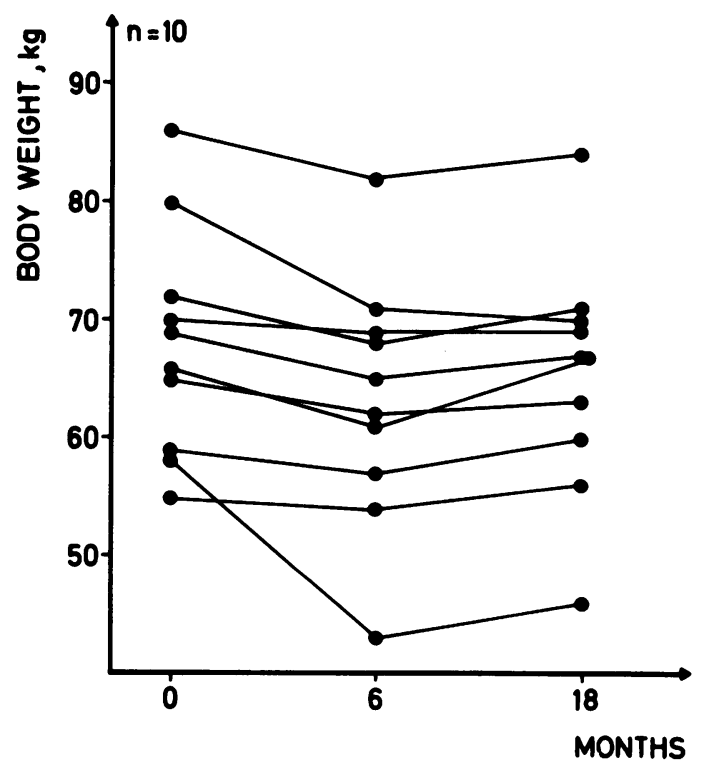

Fig. 5 Body weight before and six and 18 months after partial ileal by-pass surgery. 
oxalic acid increased slightly but significantly ( $p$ $<0.05$ ) in several patients. Six and 18 months postoperatively the median urinary oxalic acid was 54 and $51 \mathrm{mg} / 24$ hours corresponding to a median increase by 86 and $76 \%$ respectively. Postoperative intestinal ${ }^{14} \mathrm{C}$-oxalate absorption correlated with renal oxalate excretion $(r=0.70, \mathrm{p}<0.05)$. Eighteen months postoperatively, intravenous urography in these 10 patients revealed no instances of urolithiasis.

Absorption of calcium decreased significantly ( $p$ $<0.05$ ) from median 17 to $14 \%$ (corresponding to a median decrease of $18 \%$ ) after six months. The effect persisted at 18 months' follow-up (median 14\%) (Fig. 7). The reduction in calcium absorption did not correlate significantly with increases in faecal fat excretion in individual patients $(r=0.47$, p $>0.05$ ). A decrease in bone mineral content in eight patients studied 18 months postoperatively was statistically insignificant (median $-2 \cdot 1 \%$ ). Serum calcium and alkaline phosphatase were unaffected.

No cholelithiasis developed in eight patients studied by peroral cholecystography both before and 18 months after the operation.

Serum alanine aminotransferase increased transiently in six of 10 patients during the first two postoperative months. Serum iron was somewhat reduced during the first months postoperatively, but it was thereafter normal with minor or no peroral

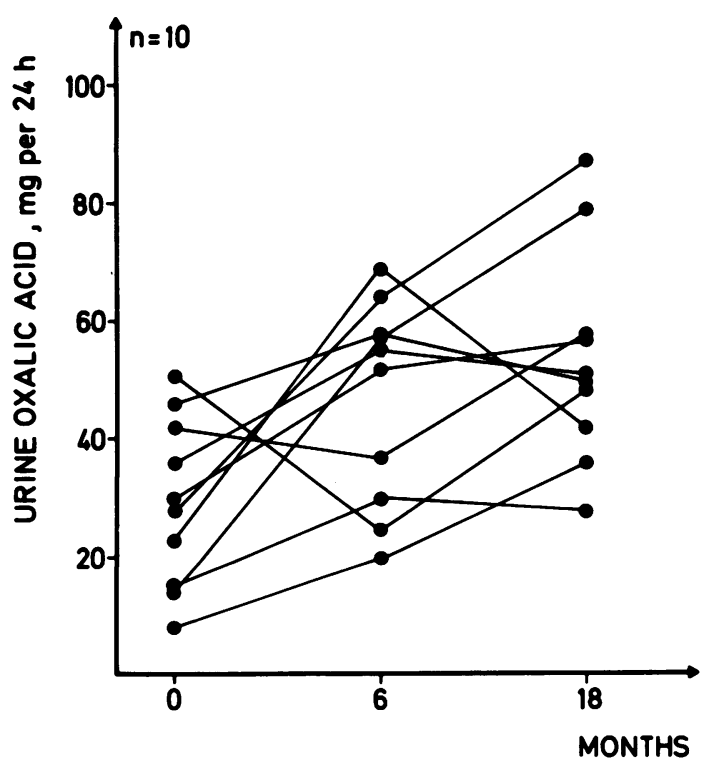

Fig. 6 Urinary oxalic acid before and six and 18 months after partial ileal by-pass surgery. iron supplementation. Other routine blood variables were unchanged (haemoglobin, transferrin, albumin, prothrombin, bilirubin, sodium, potassium, magnesium, creatinine, standard bicarbonate).

\section{Discussion}

The lowering effect on plasma cholesterol of the partial ileal by-pass operation exceeds substantially that obtained in a closely similiar group of patients treated with neomycin $(23 \%)$ or cholestyramine $(27 \%) .^{12}$ This agrees well with reports from other groups. ${ }^{13}$ The reduction in plasma cholesterol was entirely due to a fall in low-density lipoprotein, the class of lipoproteins specifically raised in familial hypercholesterolaemia. No changes occurred in total high-density lipoprotein, but our study does not preclude changes within this heterogeneous class of lipoproteins. The triglyceride-rich lipoproteins, very low-density lipoprotein, were also unchanged. In an early study, ${ }^{3}$ Buchwald et al reported a gradual increase in plasma triglycerides months and years postoperatively in patients with type IIa hyperlipoproteinaemia, but, in a later study, ${ }^{14}$ the effect of the operation on tryglycerides and very low-density lipoprotein was more variable.

We made no attempt to evaluate the possible beneficial effects of the reduction in lipoprotein on

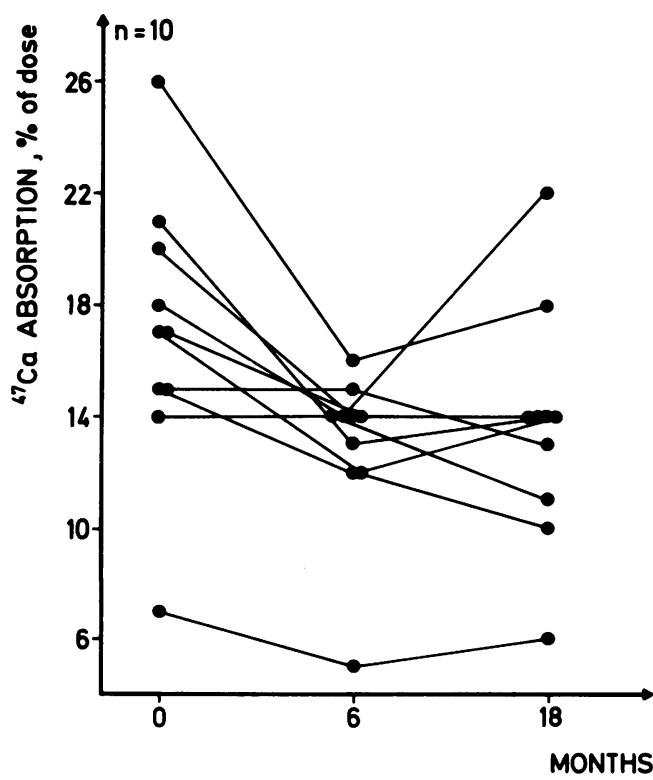

Fig. 7 Absorption of dietary calcium before and six and 18 months after partial ileal by-pass surgery. 
the atherosclerotic process. This is the subject of a much larger, on-going, secondary prevention trial using the partial ileal by-pass operation. ${ }^{15}$ Our patients PB and FP died $1 \frac{1}{2}$ and three years after the operation with acute myocardial infarction. Both patients had suffered from ischaemic heart disease preoperatively as evidenced by prior myocardial infarction and typical angina pectoris, respectively. Other deaths did not occur.

Weight loss, although substantial in several patients, was not a clinical problem. In our patients, however, diarrhoea and steatorrhoea were not transient as found by some ${ }^{3}$ but not all $^{16}$ previous workers. The severity of the problem varies and has caused one of our patients (IC) to request restoration of intestinal continuity, which promptly relieved her symptoms. In general, the problem, if present, can be managed by careful medication with antidiarrhoeal drugs, bile acid sequestering drugs to reduce bile acid concentrations in the colon, and low intake of dietary fat.

About half of the patients developed some degree of hyperoxaluria due to increased absorption of dietary oxalate. ${ }^{17}$ None of the patients, however, has to date developed urolithiasis.

Similarly, none of the patients studied by cholecystography 18 months after the operation had developed cholelithiasis. This agrees with findings by Buchwald et $a l^{3}$ and is consistent with the experience with bile acid sequestering drugs, ${ }^{18}$ the mechanism of action of which resembles that of the ileal by-pass.

The transient rise in serum alanine aminotransferase was less pronounced and of shorter duration than that observed after jejunoileal shunt for obesity, ${ }^{19}$ but it obviously suggests similiar, transient liver damage. To our knowledge, no study has indicated long-term liver damage. Malabsorption of vitamin $B_{12}$ occurs after partial ileal by-pass, ${ }^{20}$ and we therefore administer injections of vitamin $B_{12}$ every three months.

An important finding of the present study was reduced absorption of dietary calcium from the intestine. The reduction corresponded to that observed in obese patients subjected to jejunoileal by-pass. $^{2122}$ Results of bone densitometry 18 months postoperatively were inconclusive, and at this point we have considered it unwise not to assume that, with time, these patients will develop some degree of premature halisteresis. To prevent this, if this is possible, we prescribe for our patients $1000 \mathrm{mg}$ calcium and 1800 units vitamin $\mathrm{D}\left(\mathrm{D}_{2}\right.$ and $D_{3}$ ) daily.

Familial hypercholesterolaemia is a disease that often causes premature ischaemic heart disease and death. At present, the effective reduction of low density lipoprotein concentrations that can be obtained with the partial ileal by-pass operation seems very desirable. It is apparent from this study, however, that the procedure has metabolic sideeffects the importance of which is not necessarily minor. Moreover, it imposes bothersome gastrointestinal symptoms on the patients, and it does not free them from drugs and continued medical care. We continue to recommend it to patients with familial hypercholesterolaemia only if drug treatment has been tried and found ineffective, either because of the patient's inability to comply or because of lack of response despite good compliance.

This work was supported by grants from the Danish Heart Foundation, Kong Christian den X's Foundation, the Foundation for the Advancement of Medical Sciences, and P Carl Petersen's Foundation. We thank Ninna Buch Petersen, Grethe Sejersen, and Irma Stannius for expert technical assistance, and Marianne Lønning for her aid in preparation of the manuscript.

\section{References}

1 Andersen T, Juhl E, Quaade F. Jejuno-ileal by-pass for obesity - what can we learn from a literature study? $\mathrm{Am}$ J Clin Nutr 1980; 33: 440-5.

2 The dietary management of hyperlipoproteinaemia. U.S. Department of Health, Education and Welfare Publication no. 73-110. Bethesda, Md: National Institutes of Health, 1973.

3 Buchwald H, Moore RB, Varco RL. Surgical treatment of hyperlipidemia. Circulation 1974; 49: suppl. 1; 1-37.

4 Burstein $M$, Samaille J. Sur un dosage rapide du cholesterol lie aux $\alpha$ - et aux $\beta$ - lipoproteines du serum. Clin Chim Acta 1960; 5: 609.

5 Abell LL, Levy BB, Brodie BB, Kendall FE. A simplified method for the estimation of total cholesterol in serum and demonstration of its specificity. $J$ Biol Chem 1952; 195: 357-66.

6 Soloni FG. Simplified manual micromethod for determination of serum triglycerides. Clin Chem 1971; 17: 529-34.

7 Hylander E, Jarnum S, Keldsbo IL, Thale M. Standardized ('trifixed') diet in the study of chronic malabsorption syndromes. Scand J Gastroenterol 1978; 13: 423-31.

8 Kamer JH, Bokkel Huinink H, Weyers HA. Rapid method for the determination of fat in feces. $J$ Biol Chem 1949; 177: 347-55.

9 Archer HE, Dormer AE, Scowen EF, Watts RWE. Studies on the urinary excretion of oxalate by normal subjects. Clin Sci 1957; 16: 405-11.

10 Curtis FK, Fellows H, Rick C. Estimation of human 
calcium absorption by external radioisotope counting. $J$ Lab Clin Med 1967; 69: 1036-41.

11 Madsen S, Ølgaard K, Ladefoged J. Degree and course of skeletal demineralization in patients with chronic renal insufficiency. Scand J Urol Nephrol 1978; 12: 243-49.

12 Faergeman $O$. Effects and side-effects of treatment of hypercholesterolemia with cholestyramine and neomycin. Acta Med Scand 1973; 194: 165-7.

13 Miettinen TA, Lempinen M. Cholestyramine and ileal by-pass in the treatment of familial hypercholesterolaemia. Eur J Clin Invest 1977; 7: 509-14.

14 Moore RB, Buchwald H, Varco RL et al. The effect of partial ileal by-pass on plasma lipoproteins. Circulation 1980; 62: 469-76.

15 Moore RB, Long JM, Matts JP, Ampletz K, Varco RL, Buchwald H, POSCH. Plasma lipoproteins and coronary arteriography in subjects in the program on the surgical control of the hyperlipidemias. Atherosclerosis 1979; 32: 101-19.

16 Helsingen N, Rootwelt K. Partial ileal by-pass.
Kirurgisk behandling av hyperkolesterolemi. Nord Med 1969; 82: 1409-15.

17 Earnest DL. Enteric hyperoxaluria. Adv Intern Med 1979; 24: 407-27.

18 Meinertz H, Færgeman O. Drugs affecting lipid metabolism. In: Dukes, MNG ed. Side effects of drugs annual 2. Amsterdam: Excerpta Medica, 1978.

19 Danö P, Nielsen OV, Petri 'M, Jörgensen B. Liver morphology and liver function before and after intestinal shunt operation for obesity. Scand $J$ Gastroenterol 1975; 10: 409-16.

20 Buchwald $H$. Vitamin $B_{12}$ absorption deficiency following by-pass of the ileum. Am J Dig Dis 1964; 9: 755-59.

21 Danö P, Christiansen C. Calcium malabsorption and absence of bone decalcification following intestinal shunt operation for obesity. Scand J Gastroenterol 1978; 13: 81-5.

22 Hylander E, Jarnum S, Kempel K, Thale M. The absorption of oxalate, calcium, and fat after jejunoileal by-pass. Scand J Gastroenterol 1980; 15: 343-8. 